\title{
Analysis of Cow's Vocalization Number at the Estrus Period in the Traditional Farm in Yogyakarta Special Region, Indonesia
}

Yosua Kristian $\mathrm{Adi}^{{ }^{1 *}}$, Irma Padeta ${ }^{2}$, Surya Agus Prihatno

${ }^{1}$ Department of Reproduction and Obstetrics, Faculty of Veterinary Medicine, Universitas Gadjah Mada, Indonesia

${ }^{2}$ Department of Anatomy, Faculty of Veterinary Medicine, Universitas Gadjah Mada, Indonesia

DOI: $10.36347 /$ sjavs.2020.v07i04.002

| Received: 20.04.2020 | Accepted: 27.04.2020 | Published: 30.04.2020

*Corresponding author: Yosua Kristian Adi

One of the signs of estrus in cows is a change in their behavior, such as more frequent vocalization, riding other cows, and anxiety. However, changes in cow behavior on traditional farms in Indonesia are often overlooked by farmers because they do not always observe for their livestock every time. The evaluation of changes in cow behavior, especially the vocalization, is important for developing sound-based estrus detection devices in Indonesia. This study was carried out to determine the relationship between the changes in vocalization behavior and the occurrence of estrus in Indonesian tropical cows. Five non-pregnant and non-lactating health adult crossbred cows with normal ovarian follicular dynamics from the traditional farm in the Yogyakarta Special Region of Indonesia were recorded using a voice recorder for 25 consecutive days. The vulva was examined twice a day by following these methods; check the inner vulva mucosa, examine the temperature, and rectal palpation to confirm the signs of estrus. The difference in the frequency of cow vocalization during the estrus was analyzed descriptively. From 5 cows we observed, 2 cows showed a different vocalization number at the estrus period. The estrus condition was confirmed by pinkish and reddish inner vulva mucosa, increasing of external vulva temperature and rectal palpation examination. The other 2 cows showed no signs of estrus and there were no different vocalizations numbers during the research. One cow was estrus with no different vocalizations number confirmed. From the two cows, it could be observed that there was a difference in vocalization intensity approximately more than 3 times the fold at the estrus period.

Keywords: cow, estrus, number, traditional farm, vocalization.

Copyright @ 2020: This is an open-access article distributed under the terms of the Creative Commons Attribution license which permits unrestricted use, distribution, and reproduction in any medium for non-commercial use (NonCommercial, or CC-BY-NC) provided the original author and source are credited.

\section{INTRODUCTION}

Estrus is the period of acceptance of the male for copulation. Ovulation usually occurs in this period in most domestic animals, except the cows, where it occurs about 12 hours after the end of estrus [1]. The right time to do artificial insemination in the cow is at the 4-14 hour following the onset of estrus or 12 to 24 hours before the ovulation [2,3]. The duration of the normal estrus cycle in the cow is 18-24 days. It consists of two-phase, a luteal phase (14-18 days) and a follicular phase (4-6 days) [4]. The estrus occurs at the end of the follicular phase and the expression of standing estrus is only shown for a short period, about 5 to $7 \mathrm{~h}[5,6]$.

GnRH, FSH, LH, estrogen, progesterone are the main reproductive hormones that work together to regulate the estrus cycle. Ovarian functions, such as the growth of follicle, ovulation, luteinization, and luteolysis are regulated by the endocrine hormones of the hypothalamus $(\mathrm{GnRH})$, anterior pituitary (FSH and
LH), ovaries (progesterone, oestradiol, and inhibins) and the uterus (prostaglandin) [4]. Estrogen reaches the peak concentration in the blood circulation during the estrus period [7]. The high level of estrogen in the blood circulation has an important role in regulating a cascade of physiological events necessary for the successful reproduction of the cow. This will induce the expression of estrus behavioral for successful mating $[8,9]$, such as more frequent vocalization, mounting other cows, and anxiety.

The detection of estrogen in the blood is expensive rather than the detection of behavioral change. Observation of the cow's vocalization is an easier method to detect the estrus. But the farmers must spare more time to observe their cows. For Indonesian traditional farmers, farming is not their main job. Usually, they are just spare their time twice, in the morning and afternoon to observe their cow when they give the grass/feed. So that, the estrus period of their cow often overlooked. 
Vocalization of the animal has been studied by many researchers such as vocalization analysis of dairy cows [10], cattle mother-offspring contact calls [11], a sheep vocalization case study [12], vocal communication and the importance of mother-offspring relation in cattle [13]. However, an analysis of the frequency of Indonesian cow's vocalization in the traditional farm has never been done, especially in the estrus period. This research aim is to observe the possibility of different vocalization frequency of Indonesian cows in the estrus period that maintained in a traditional farm in which has a tropical climate.

The data can be used as preliminary data that important in future research to develop the estrus detection device based on the vocalization sound in the Indonesian farm. Appropriate estrus detection will increase the success of artificial insemination in cows and help this country to increase the cow population.

\section{MATERIAL AND METHOD Ethical approval}

This research has been approved by the Ethical Committee of Faculty of Veterinary Medicine, Universitas Gadjah Mada with letter No: 0061/ECFKH/Int./2019.

\begin{abstract}
Animals
Five non-pregnant and non-lactating, health, adult, multiparous, crossbred, meat cows with normal ovarian follicular dynamics from the traditional farm in the Yogyakarta Special Region of Indonesia were used as a sample in this study. The normal ovarian follicular dynamics were proved by the rectal palpation examination to find the development of follicle and corpus luteum. All cows were maintained in the individual barn.
\end{abstract}

\section{Experimental design}

The vocalization of five cows was recorded using a voice recorder (Stereo IC Recorder, ICDPX470, Sony $®)$ that could record approximately 40 hours with REC mode LPCM $44.1 \mathrm{kHz} / 16$ bit for 25 consecutive days. The recording was done inside the barn and the recorder was laid out in the part of the barn with the distance approximately 2 meters from the cow. The file and battery were replaced every day in the afternoon. The vulva was observed to confirm the occurrence of estrus twice a day. The mucosa of the inner vulva was photographed using a digital camera. The external temperature of the vulva was examined using Non-contact Infrared Thermometer® with effective distance $5-15 \mathrm{~cm}$, range body temperature 32 -
$42,9 \mathrm{oC}$, and accuracy $\pm 0,2 \mathrm{oC}$. Rectal palpation was carried out by inseminator when the cow showed estrus signs such as there was thin, clear, and watery mucous discharge from the vulva, vocalization with more intensity, and swollen-reddish vulva as the farmer saw it. All the observation was carried out in one traditional farm with individual barn located in Sleman, Yogyakarta Special Region, Indonesia.

\section{Analysis}

The vocalization of the cows was counted based on the sound that identified from the recorder. The vocalization was counted in the day that cow showed signs of estrus, such as there was transparent mucous discharge from the vulva, increased vulva temperature, and reddish mucosa. The vocalization counted on the day of estrus was compared with vocalization counted one day before and after estrus. The result was analyzed descriptively.

\section{RESULTS AND DISCUSSION}

The research was carried out on one traditional farm in Yogyakarta Special Region, Indonesia. A rectal palpation examination was performed for all cow candidates before the research begin. Five female adult cows that had normal ovarian follicular dynamics due to rectal palpation, proved by the presence of corpus luteum and developing follicle, were chosen as research animals. Unfortunately, cow number 4 was estrus after the rectal palpation and got AI before we recorded its vocalization. The external temperature of the vulva was increased up to $37,8^{\circ} \mathrm{C}$ and there was transparent mucous discharge from the vulva. Based on the result of our observation for 25 days in all the five cows, cow number 1 and 2 not showed good estrus signs, although there was a day that the external vulva temperature increased up to $37,4^{\circ} \mathrm{C}$. The daily temperature of the external vulva in all observed cows was ranged from $36,8^{\circ} \mathrm{C}$ to $37,2^{\circ} \mathrm{C}$. However, this increase in temperature was not followed by the change in vocalization activities. Cow numbers 3 and 5 showed a good sign of estrus. The vulva mucosa was pink and reddish. Based on the information we got from the farmer, there was transparent mucous discharge from the vulva. The external temperature of vulva's cow number 3 was increased up to $37,5^{\circ} \mathrm{C}$. However, we are not got the temperature data of vulva's cow number 5 because of the tool troubles. Estrus condition was confirmed by rectal palpation examination and the inseminator did artificial insemination of cow number 3 and number 5 . The signs observed in the day of estrus could be seen in table 1 . 
Table-1: The signs observed on the day of estrus.

\begin{tabular}{|l|c|c|c|c|}
\hline & \multicolumn{3}{|c|}{ Day of Estrus } \\
\hline Color of Vulva Mucosa & $\begin{array}{c}\text { Vulva External } \\
\left.\text { Temperature ( } \mathbf{(}^{\mathbf{C}} \mathbf{C}\right)\end{array}$ & Rectal Palpation & Vocalization \\
\hline Cow 1 & Pink & 37,4 & No & No \\
\hline Cow 2 & N/A & 37,4 & No & No \\
\hline Cow 3 & Pinkish & 37,5 & Yes, followed with AI & $>3 x$ \\
\hline Cow 4 & Reddish & 37,8 & Yes, followed with AI & N/A \\
\hline Cow 5 & Reddish & N/A & Yes, followed with AI & $>3 x$ \\
\hline
\end{tabular}

$\mathrm{NA}=$ not available, $\mathrm{AI}=$ artificial insemination

The vocalization number analysis from recorder showed that there was a different number of vocalizations activities in cow number 3 and number 5 during the estrus period. Cow number 3 showed the number of vocalizations 42 times at the period of estrus for 7 hours. This was approximately 3 times more than usual vocalization at the day before the estrus period at the relatively same time, 12 times of vocalization. Even more, there was no vocalization one day after the estrus period. Cow number 5 showed an extreme change of vocalization number than usual. One day before the estrus period, cow number 5 just showed 10 times vocalization, but change up to 283 times at the estrus period. This was 3 times or almost 4 times more than vocalization number one day after the estrus period with 71 times vocalization. This was an interesting observation that there was a change of vocalization intensity in the estrus period of Indonesian tropical cows that maintained in one traditional farm located outside of the village. The vocalization number of cow's number 3 and number 5 one day before, one day after, and at the estrus period could be seen in table 2 .

Table-2: The difference of vocalization number in the one day before, one day after, and on the day of the estrus period for 7 hours of two cow samples

\begin{tabular}{|c|c|c|c|c|c|c|c|c|c|}
\hline & & $\mathbf{h 1}$ & $\mathbf{h 2}$ & $\mathbf{h 3}$ & $\mathbf{h 4}$ & $\mathbf{h 5}$ & $\mathbf{h 6}$ & $\mathbf{h 7}$ & $\begin{array}{c}\text { Vocalization } \\
\text { number }\end{array}$ \\
\hline \multirow{3}{*}{ Sample Cow number 3 } & $\mathrm{d}-1$ & 10 & 2 & 0 & 0 & 0 & 0 & 0 & 12 \\
\cline { 2 - 11 } & $\mathrm{d}-\mathrm{es}$ & 5 & 10 & 16 & 4 & 5 & 2 & 0 & 42 \\
\cline { 2 - 11 } & $\mathrm{d}+1$ & 0 & 0 & 0 & 0 & 0 & 0 & 0 & 0 \\
\hline \multirow{3}{*}{ Sample Cow number 5 } & $\mathrm{d}-1$ & 1 & 3 & 1 & 0 & 0 & 4 & 1 & 10 \\
\cline { 2 - 10 } & $\mathrm{d}-\mathrm{es}$ & 111 & 118 & 10 & 8 & 20 & 15 & 1 & 283 \\
\cline { 2 - 9 } & $\mathrm{d}+1$ & 28 & 12 & 15 & 16 & 0 & 0 & 0 & 71 \\
\hline
\end{tabular}

$\mathrm{d}-1=$ one day before estrus, $\mathrm{d}+1=$ one day after estrus, $\mathrm{d}-\mathrm{es}=$ the day of estrus

Estrogen plays an important role in the occurrence of estrus and influences estrus behavior. Exogenous estrogen administration in the cow will lead to increase a sign of estrus, such as attempted mounts, successful mounts, stands, chin rests, and sniffing vulva. Estrogen, especially estradiol, becomes the main signal to the brain that will induce the expression of estrus, but this only happens in the absence of progesterone [14]. In the commercial farm, the focus detection of estrus in the cow is the observation of standing heat [15]. But, in the traditional farm, especially in Yogyakarta Special Region, Indonesia, the detection of estrus in the cow by the farmer was depending on the observation of external signs, such as swollen-reddish vulva, clear and watery mucous discharge from the vulva, more intense vocalization, and mounting the other cow. During the estrus period, the higher concentration of estrogen than progesterone in blood circulation affects a greater quantity of blood flowing through the uterine vascular bed [16]. Administration of estrogen in human and animal have the same effect that will make vasodilatation of blood vessel [17]. This causes swelling and redness of the cow's vulva in the period of estrus when the estrogen reaches the peak in the blood circulation. This reddish or pinkish was seen in the vaginal mucosa of cow number 3, number 4, and number 5 at the period of estrus. The increasing temperature in the vulva likely has a relation with the vasodilatation of peripheral blood vessels. This confirmed in Bali cow that vaginal temperature was ranged from $37,4 \mathrm{oC}$ to $38,39 \mathrm{oC}$ during the estrus cycle with the highest temperature was in the estrus period [18]. This report was slightly different from our result because we used different tools. We use a non-contact infrared thermometer to examine the external temperature of the vulva. However, the previous report used a digital thermometer to examine the inner temperature of the vagina. The inner temperature of the body part was higher than the external body part due to the environment. The highest temperature of external vulva we observed was $37,80 \mathrm{C}$ in cow number $4,37,5 \mathrm{oC}$ in cow number 3 , and $37,4 \mathrm{oC}$ in cow number 1 and number 2 . This was different than the daily external vulva temperature we observed that ranged from $36,80 \mathrm{C}$ to $37,2 \mathrm{oC}$. During the estrus period, there was watery mucus discharge from the vagina [19]. This mucus was secreted by the cervix under the influence of estrogen [20,21]. Cervical mucus discharge is a mechanical barrier against the pathogen of the uterus. Besides, this mucous also has a great 
influence on conception [22]. Cow number 3, number 4 , and number 5 showed great mucous discharge from the vulva. Based on that, the farmer called inseminator to do rectal palpation examination and artificial insemination.

Vocalization is one way for cows to communicate. Vocalization of the cow expressed many thinks such as stress [10], mother-offspring contact $[11,13]$, and estrus [23]. Observing the intensity of vocalization is an easier way to detect estrus. However, many farmers have no time to observe their cows all day. Even more, the cow with poor nutrition sometimes show no signs of estrus. This condition could be classified as silent heat. In our research, we analyzed only two cows that showed a different intensity of vocalization. The other cows we observed not showed a different intensity of vocalization. Cow number 3 showed a difference in intensity of vocalization at night, around $7 \mathrm{pm}$ until $2 \mathrm{am}$. For 7 hours, there was approximately 42 times vocalization. One day before the estrus period, at the relatively same time, cow number 3 only showed 12 times vocalization and one day after estrus showed no vocalization. The vocalization was changed more than a 3-time fold. Same as cow number 3, cow number 5 also showed a change of vocalization number. In the period of estrus, in the morning, around 8 am until $3 \mathrm{pm}$, cow number 5 showed 283 times of vocalization. One day before estrus, cow number 5 only showed 10 times of vocalization and one day after estrus showed 71 times of vocalization. Same with cow number 3, the vocalization was changed more than 3 times fold. Based on our research, we found the interesting observation that changing up to 3 times a fold of vocalization number may be the indication of estrus in the cow that maintained in the traditional farm, Indonesia.

\section{CONCLUSION}

Based on the research, we found that two from five cows sample showed a different number of vocalizations during the estrus period. There were changes more than 3 times the fold of vocalization number at the estrus period of two cow samples that observed in the traditional farm of Indonesia. The estrus condition was confirmed by pinkish-reddish inner vulva mucosa, increasing of the external vulva temperature, and rectal palpation examination. It still needs further study with larger cow samples to get confirmation about the relationship of cow's vocalization intensity with estrus.

\section{ACKNOWLEDGMENT}

The authors would like to say thank to Research Directorate of Universitas Gadjah Mada for the funding support so the team could conduct and finished this study.

\section{REFERENCES}

1. Noakes DE, Parkinson TJ, England GCW. Arthur's veterinary reproduction and obstetrics, $8^{\text {th }}$ ed. China: WB Saunders. 2008: 3-53.

2. Roelofs JB, Graat EAM, Mullaart E, Soede NM, Voskamp-Harkema W, Kemp B. Effects of insemination-ovulation interval on fertilization rates and embryo characteristics in dairy cattle. Theriogenology. 2006; 66:2173-2181.

3. Roelofs JB, van Erp-van der Kooij E. Estrus detection tools and their applicability in cattle: Recent and perspectival situation. Anim Reprod. 2015;12(3):498-504.

4. Forde N, Beltman ME, Lonergan P, Diskin M, Roche JF, Crowe MA. Oestrous cycles in Bos Taurus cattle. Anim Reprod Sci. 2011; 124:163169.

5. Roelofs JB, Van Eerdenburg FJCM, Soede NM, Kemp B. Various behavioral signs of estrous and their relationship with time of ovulation in dairy cattle. Theriogenology. 2005; 63:1366-1377.

6. Sveberg G, Refsdal AO, Erhard HW, Kommisrud E, Aldrin M, Tvete IF, Buckley F, Waldmann A, Ropstad E. Behavior of lactating Holstein-Friesian cows during spontaneous cycles of estrus. J Dairy Sci. 2011; 94:1289-1301.

7. Lyimo ZC, Nielen M, Ouweltjes W, Kruip TAM, van Eerdenburg FJCM. Relationship among estradiol, cortisol and intensity of estrous behavior in dairy cattle. Theriogenology. 2000; 53(9):17831795.

8. Ireland JJ. Control of follicular growth and development. J Reprod Fertil Suppl. 1987; 34:3954.

9. Frandson R, Wilke WL, Fails AD. Anatomy and physiology of farm animals. Baltimore: Lippincott Williams and Wilkins; 2003.

10. Meen GH, Schellekens MA, Slegers MHM, Leenders NLG, van der Kooij E, Noldus LPJJ. Sound analysis of dairy cows. Proceedings of Measuring Behavior. The Netherlands: Wageningen; 2014.

11. de la Torre MP, Briefer EF, Reader T. Acoustic analysis of cattle (Bos taurus) mother-offspring contact calls from a source-filter theory perspective. Appl Anim Behav Sci. 2015; 163:5868.

12. Bishop JC, Falzon G, Trotter M, Kwan P, Meek PD. Sound analysis and detection, and the potential for precision livestock farming - a sheep vocalization case study. Proceedings of $1^{\text {st }}$ AsianAustralasian Conference on Precision Pastures and Livestock Farming; 2017.

13. de la Torre MP, McElligott AG. Vocal communication and the importance of motheroffspring relations in cattle. ABC. 2017; 4(4):522525.

14. Vailes LD, Washburn SP, Britt JH. Effects of various steroid milieus or physiological states on sexual behavior of Holstein cows. J Anim Sci. 1992; 70:2094-2103. 
15. Roelofs J, Lopez-Gatius F, Hunter RHF, Van Eerdenburg FJCM, Hanzen Ch. When is a cow in estrus? Clinical and practical aspects. Theriogenology. 2010; 74:327-344.

16. Ford SP. Control of uterine and ovarian blood flow throughout the estrous cycle and pregnancy of ewes sows and cows. J Anim Sci. 1982; 55(2):32-42.

17. Tostes RC, Nigro D, Fortes ZB, Carvalho MHC. Effects of estrogen on the vascular system. Braz J Med Biol Res. 2003; 36:1143-1158.

18. Indira PN, Kustono, Ismaya. The profile of vaginal temperature and cytology of vaginal smear in Bali cattle during estrus cycle phase. J Indonesian Trop Anim Agric. 2014; 39(3):175-179.

19. Bernardi S, Rinaudo A, Marini P. Cervical mucus characteristics and hormonal status at insemination of Holstein cows. IJVR. 2015; 17(1):45-49.
20. Marinov U, Lovell JE. Secretory and ciliated cells of the bovine cervix. Am J Vet Res. 1967; 28(127):1763-1772.

21. El-Banna AA, Hafez ES. The uterine cervix in mammals. Am J Obstet Gynecol. 1972; 112(1):145-164.

22. Lim HJ, Son JK, Yoon HB, Baek KS, Kim TI, Jung YS, Kwon EG. Physical properties of estrus mucus in relation to conception rates in dairy cattle. $\mathbf{J}$ Anim Reprod Biotechnol. 2014; 29(2):157-161.

23. Chung Y, Lee J, Oh S, Park D, Chang HH, Kim S. Automatic detection of cow's oestrus in audio surveillance system. Asian. Australas. J Anim Sci. 2013; 26(7):1030-1037. 